\title{
Automated Coconut Plantation System
}

\author{
Sajfan, K. E. Prakash, Nethravathi P.S
}

\begin{abstract}
This work basically deals with the coconut plantation and is designed by using Internet Of Things (IOT) devices, web and android $O S$ to manage the coconut farm. The system efficiently control, monitor and manage the activities of the coconut farm. The details of the coconut that has less amount of water which will be monitored and provide water supply for particular tree. The collection of devices in the system provides alert to the concerned person who maintenance the farm, when there is any leakage occurring in the water supply. The objective of automating the coconut plantation system is to reduce the work of the people in the of water or urea in the field.

Keywords: Internet Of Things, Android, iOS, Coconut farm, Field, Man power.
\end{abstract}

\section{INTRODUCTION}

\section{Existing system}

In the present scenario coconut farming is controlled and monitored by farmers manually. The system requires more manpower in the agricultural field. The proposed system is an automated coconut plantation system by using Internet of Things. This project is designed to capture and monitor the quantity of water, urea and pesticides in the agricultural field. This system can give alert to the Subadmin and Admin when there is any leakage occurring while water supply.

\section{Purpose}

- Agricultural field will be monitored by a single person

- Structured way of data can be maintained

- Man power is reduced

\section{Scope}

- Control and monitor the temperature, humidity, soil moisture and the quantity of water in the coconut tree in the rural field

- Automatically provide water to the coconut tree when there is less measure of water in the soil

- Provide the information about the location, device monitoring, their employee details and attendance

- Online framework used to control and monitor the activities, not depending on the workers/formers

- Attendance details of the workers and their salary is

Revised Manuscript Received on May 15, 2020.

* Correspondence Author

Mr. Sajfan*, Department of MCA, Shree Devi Institute of Technology, Mangalore, Karnataka, India.

Dr. K.E. Prakash, Director of Shree Devi Institute of Techonology, Mangalore.

Dr.Nethravathi P.S, Professor of Department of Master of Computer Applications at Shree Devi Institute of Technology, Mangalore.

(C) The Authors. Published by Blue Eyes Intelligence Engineering and Sciences Publication (BEIESP). This is an open access article under the CC BY-NC-ND license (http://creativecommons.org/licenses/by-nc-nd/4.0/) calculated in this work.

\section{LITERATURE SURVEY}

In the Existing system, the agricultural field consists of many workers to inspect whether the coconut tree is has sufficient water and also the workers provide the water supply to the particular tree when there is any shortage of water. It is time consuming for the workers to pump the water manually. In the automated system, the Android OS is used, which gives better performance for the low cost [5]. In the automated system, agricultural field uses few workers and minimizes water wastages. It provides the temperature, humidity of specific coconut tree and the data about the coconut tree monitoring are stored on the server. Fast changes to the settings to enable or disable tasks became easier in automated system using Android [5].

\section{Feasibility Study}

Primary investigation examined for project feasibility. Make sure the new system is feasible for technical, operational and economical aspects [1]. The system is user friendly and has good debugging the system. This system is operationally feasible by eliminating the work load of the workers which will reduce the time consumption and difficulty of maintenance of lacks of coconut tree. This system is very useful for agricultural field for the coconut trees and it will completely monitor the information of a particular tree. This system requires minimal cost of training because of user friendly interface of the system [2].

\section{METHODOLOGY}

Android platform is used to automate this work. The information of various modules are stored in MySQL databases. The various activities of this work designed by using various flexible modules[2]. Admin, Sub-admin, User, Product, Monitor etc. Java programming provides good functionality for resource constrained devices with high level security and connectivity [3]. Hence Java language is used in this work as it provides scalability for IOT applications.

The monitor module controls water, an temperature of the coconut plant that displays the details to the Admin. Since there is Monitor, Admin can control over the all areas of the coconut plant. Sub-admin user will have the control of their location given by the Admin and mark attendance of the Employee.

Admin looks after the overall the modules. Admin provides Sub-admin with login and password and have authority for making timely changes to the software as per the requirements. The core tasks of the Admin is to work by adding the devices, controlling the Sub-admin, and view the daily, monthly and yearly reports.

Published By:

Blue Eyes Intelligence Engineering

\& Sciences Publication

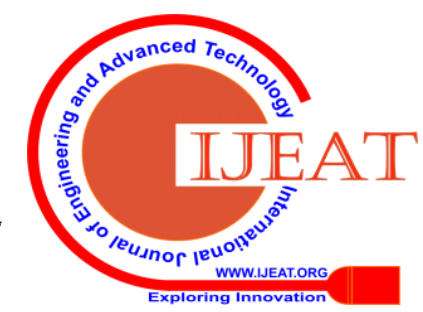




\section{Automated Coconut Plantation System}

Updating the daily routine and reports of the specific area can be forward to the Admin. One can also have control over the given location from the Admin. The Sub-admin can monitor only the given location of the Admin in the coconut farm/field. He will get the instant information on a timely basis through the website and if the water level is low, in a particular tree then the Sub-admin have the permission approve it through this android application.

Employee can change his profile in the android application and has access to change the password. The important task of Employee is that he can view his payments through the android application. Employee can view the information of the attendance of the day, which is stored in the database.

\section{Product Features}

Automated Coconut Plantation System uses IOT devices which are very helpful in future, since it screens and controls the water level in coconut tree. NodeMCU hardware monitors the flow of water, temperature and humidity. The data that comes to NodeMCU is from flow meter. It controls the water level, temperature and humidity for each individual coconut tree and also gets the attendance of the employee where they are working. It also collects the data of the employees and will be stored in the database.

2. User Levels: It has three levels of users namely Admin, Sub-admin and the Employee.

i) Admin:

She/he manages the full system.

She/he manages information of the Location, Subadmin and Devices.

She/he will get the report the devices, Location and Sub-admin details.

ii) Sub-admin:

She/he can manage devices of a particular given location.

She/he manages their employees and marks their attendance.

iii) Employee:

She/he can check the salary.

She/he can see their respective Attendance.

\section{External Interface Requirements}

\subsection{User Interfaces}

Website provides multiple interfaces to the users and provides computer operations easier [4]. The complete system is presented with a website by using IOT concept, wherein all users can login to their account. After login access to the database is given. The users can view water level, temperature, humidity and the attendance of employee.

\subsection{Software Interface}

The system requires a Wi-Fi connection in order to work properly. The programs uploaded to the micro controller and that is being placed into the NodeMCU. The program interacts with the database whenever there are any changes in data.

\section{Non-Functional Requirements}

\subsection{Performance Requirements}

The proper functions of pipes and valves may improve the efficiency and accuracy of the system. System needs good wifi connection with high transaction speed for the better performance.

\subsection{Safety Requirements}

Sub-admin should always monitor the water level, temperature and humidity of the coconut tree and also he/she need to send the daily, monthly and yearly report to the Admin. Therefore there is no chance of malicious activities.

\subsection{Other Requirements}

External micro chips and other sensors are also required for the function of this system. The complete system is controlled by the software that is stored on the NodeMCU board. As the device uses sensors and hardware, it need to be protect from other damages.

\section{SYSTEM DESIGN}

Figure-1 below demonstrates the architectural design mainly containing the entire system and the communication between them by dividing them into number of systems. Along these lines lessening their intricacy and expanding the proficiency of the framework. There are number of layers in the architecture depending on these layers it can be classified into 3-tier or n-tier architecture.

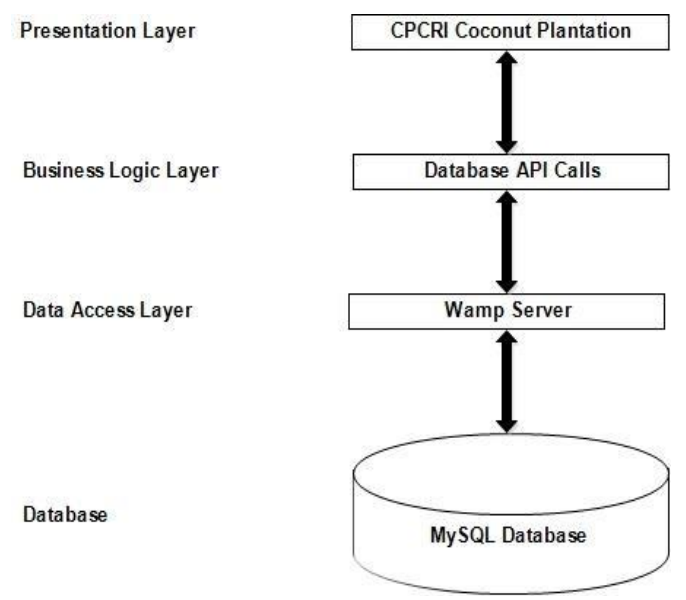

Fig.1. Architectural Design.

Framework of an Automated Coconut Plantation System is shown below in Figure-2 where the chief parts or capacities are spoken to by blocks associated by lines that demonstrate the connections of the blocks.

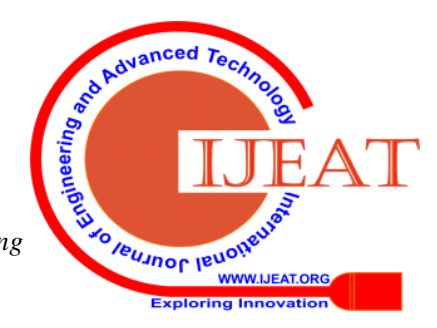




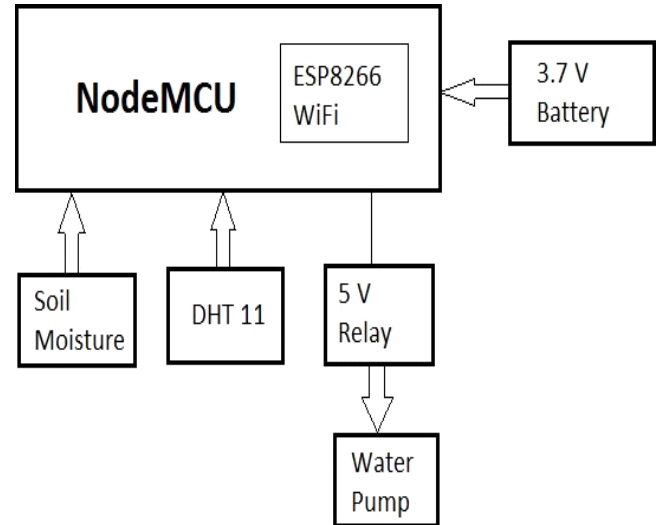

Fig.2. Framework of an Automated Coconut Plantation System

This diagram are ordinarily utilized for more elevated amount, less point by point depictions that are planned to clear up generally speaking ideas without worry for the subtleties of execution.

- NodeMCU: It includes firmware which runs on the ESP8266 Wi-Fi SoC from Espressif Systems and equipment which depends on the ESP-12 module. The expression "NodeMCU" of course alludes to the firmware as opposed to the advancement units. Here this board is used as a main controller in the system and this board will control the all sensors.

- Soil Moisture: The Soil Moisture Sensor utilizes capacitance to gauge the water dimension of soil. Just addition this tough sensor into the dirt to be tested and the volumetric water dimension of the dirt is accounted for in percent. This will pass the water level details to the NodeMCU and store it to the database.

- DHT11: Temperature \& Humidity Sensor features a temperature \& humidity sensor complex with a adjusted computerized signal output. By utilizing the restrictive computerized signal-securing system and temperature and stickiness detecting innovation, it guarantees high unwavering quality and great long haul solidness. Here it is used sense the temperature and humidity of the coconut tree and pass it to the NodeMCU from there the NodeMCU will store it to table.

- 5V Relay: Module is a relay interface board; it can be controlled directly by a wide range of microcontrollers. It utilizes a low dimension activated control signal as $5 \mathrm{~V}$ to control the transfer. Setting off the transfer works the regularly open or typically shut contacts. It is regularly utilized in a programmed control circuit. Essentially, it is a programmed change to control a high-current circuit with a low-current sign. This module is used to capture the pump to automatically leveling the water.

- Water Pump: It is used to pump the water to the coconut tree. Here in this project we are used mini water pump and it's having voltage same as relay. The pump is connected to the $5 \mathrm{~V}$ relay to control the pump. If there is signal comes from the relay depending on that it work.

Figure-3 below shows the top-level procedure of the application. It additionally communicates to the outside elements interface with the framework and to abnormal state procedures of the framework. The exercises of framework with outside substances are appeared.

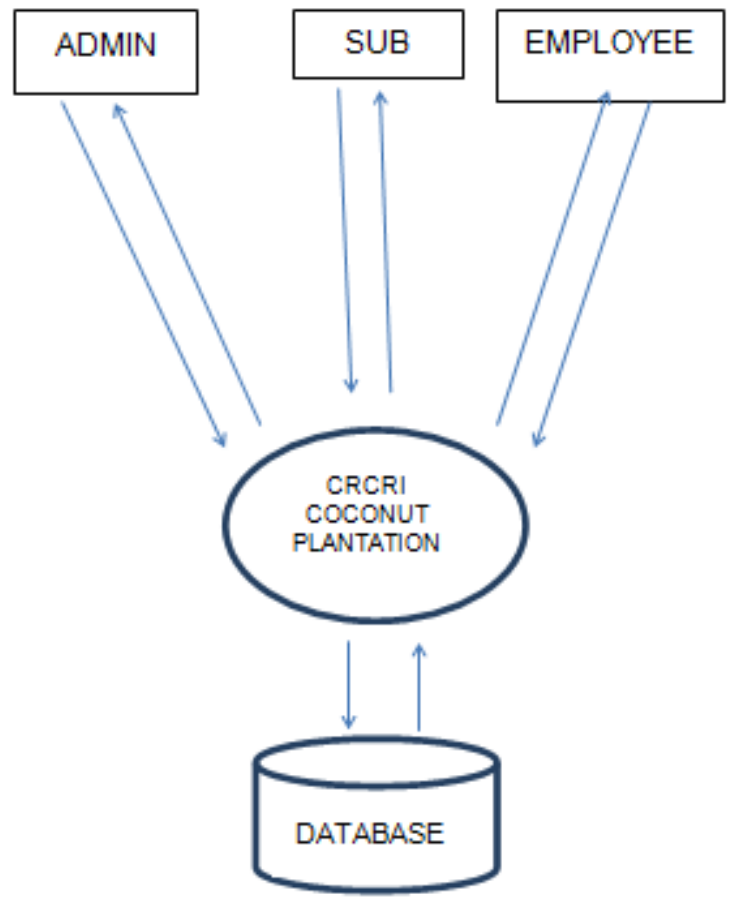

Fig.3. Context Flow Diagram of the system

Admin login to the system with email and password. After login, Admin performs different assignments such as managing location which includes Main Location, latitude, longitude, condition details. Admin also manages information of Sub-admin and then allocates Sub-admin to each location. He will also manage the details of the devices and provide the location to the devices. Admin has capacity to screen all the devices status like temperature, humidity and soil moisture in the coconut tree has ability provide water to the coconut tree if it is less. Admin will get the all report of the system like Locations, Devices, and Sub-admins.

Sub-admin logs to the mobile application with email and password. Sub-admins are allocated to each location given by Admin. He will screen the coconut tree status utilizing this mobile application. He will manage the Employee they were working under this Sub-admin in his location. The Sub-admin will mark their attendance through this android application and also he can manage their salary. These Salary and Attendance information will go the Employee's database.

Employee logs to the application with email and password. Employee are comes under the various Sub-admins. Employee can check their Salary using this android application. He can also view his attendance of the particular date were when attended. And also he can update his profile and also have choice to change their password using the application.

Here Admin Report Module is extended it into four they are location report, device report, monitor report, and Subadmin report. Location report have locations been they marked and provided to the Sub-admin. Device report will appears in the device details that are introduced in the field. Monitor will have the status of the devices from starting till ending for a given date.

Published By:

Blue Eyes Intelligence Engineering

\& Sciences Publication

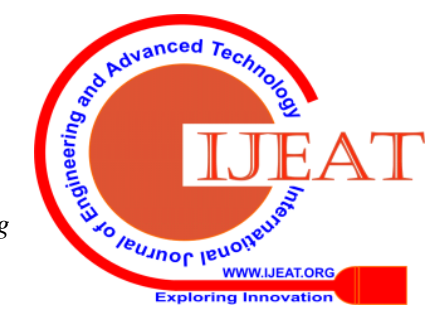




\section{Automated Coconut Plantation System}

Sub-admin report will have the report of a Sub-admin like their name, phone number, email, and provided location.

\section{- Login}

Admin needs to login with email and password.

\section{- Manage Location}

Admin manages various locations like main location and sub location as latitude and longitude to monitor the status.

- Manage Devices

Admin manages various devices and provide location to it.

\section{- Manage Sub-admin}

Admin will manage the Sub-admin in this website to provide particular location to the Sub-admin.

- Monitor Status

To see the present status of the device from the specific location.

- View Report

Admin to view the report of the location, devices and Sub-admins.

\section{RESULT \& ANALYSIS}

MONITOR STATUS : In this module the Admin can monitor and capture the process done in the devices. LOCATION : In this module the Admin can add the location and view the location that is already added to the database.

SUBADMIN : In this module Admin will register the user with their details and viewing the Sub-admins who are already registered.

DEVICES : In this module devices are managed by the Admin for monitoring and controlling purpose.

\section{REPORTS}

The following Figure-4 shows all the four reports to the Admin.

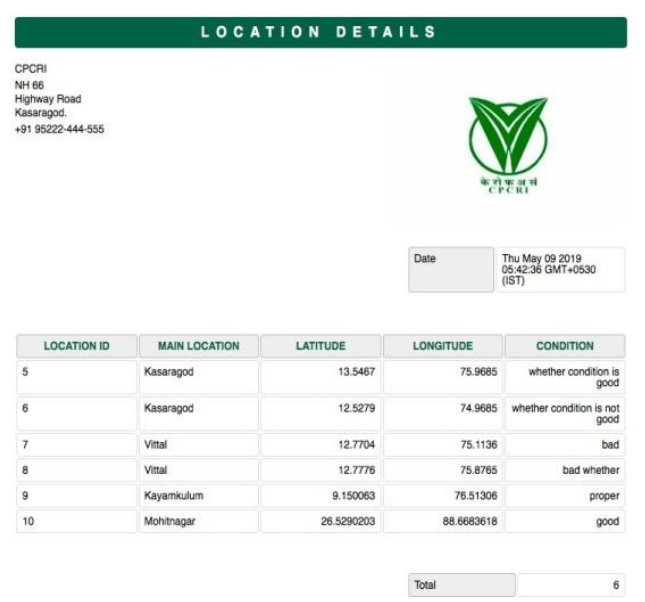

Fig.4.Various reports of the automated system.

Figure- 5 below shows various reports that can be printed by the users.

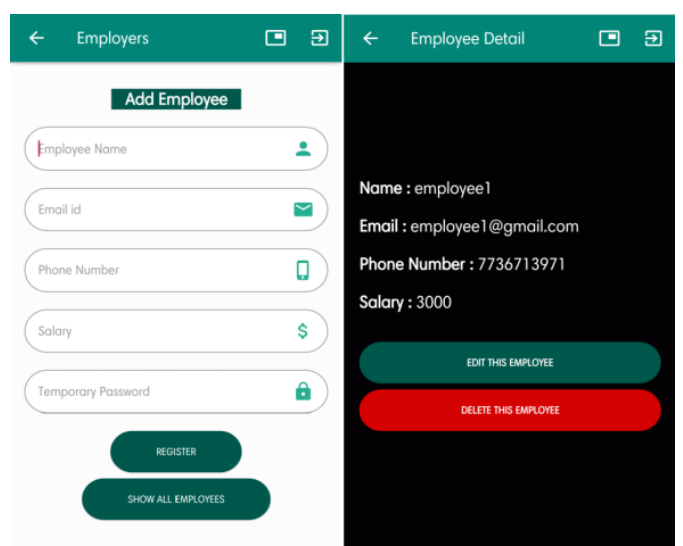

Fig. 5. To print view of various reports

Figure- 6 below used by the Sub-admin to manage the employers of the agricultural field

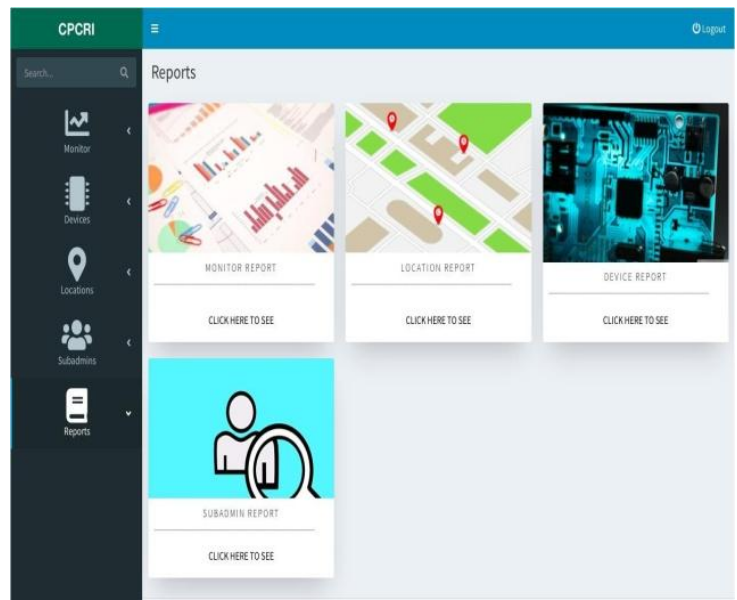

Fig. 6. Agricultural field management

By using Figure-7, Sub-admin mark the attendance of The employers who are present in from what time to till what time.

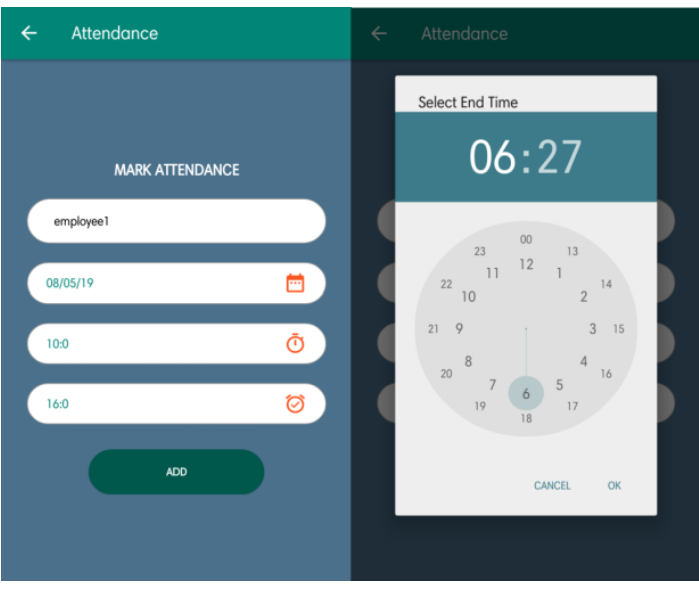

Fig.7. Attendance entry

Employees can view their salary and also he can view attendance in the Figure-8 below

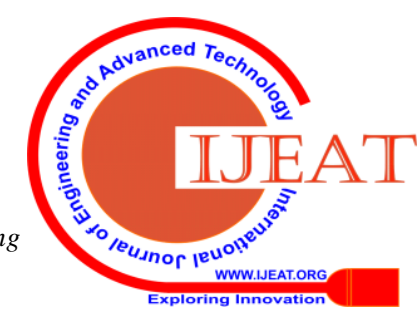




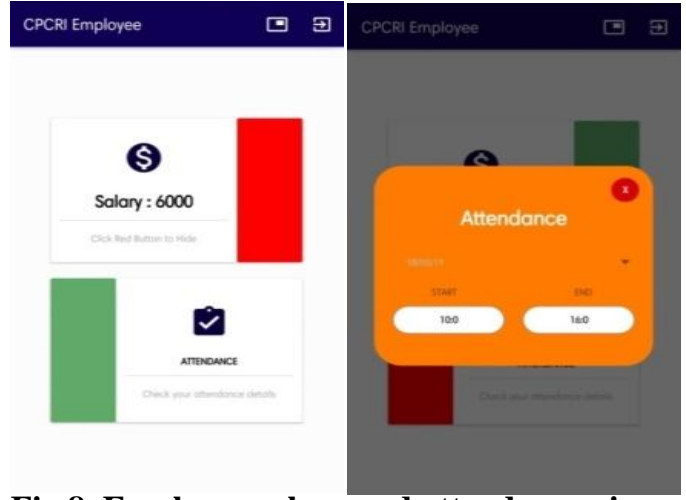

Fig.8. Employee salary and attendance view

\section{CONCLUSION}

This system can be utilized to monitor and control the water level in coconut farm. This work allows coconut tree to have different water level which can be controlled by a single person. The Administrator here can monitor the water level of the coconut tree and also he can see the temperature and humidity of the coconut tree.

Website is built in such way that it should suit for all agricultural fields in future. So every effort is taken to implement this project in automated plantation. This can be deployed to any place where people want make use of automation for coconut plantation.

\section{FUTURE ENHANCEMENT}

Application needs to evolve around the requirements of the clients. So, application should support changes in it in-order to satisfy client requirements.

- The Sub-admin monitor module can be improved in viewing devices location through the map, rather than IP Address.

- $\quad$ iOS can be utilized to develop this application so that client can easily access the application through their mobile itself.

- $\quad$ To find the location of the device, GPS can be installed in the device.

- $\quad$ Security of the framework can be increased. Client can login through mobile number and OTP can be sent to the same number.

- In mobile application security can be enhanced through finger print recognition

\section{REFERENCES}

1. Pankaj Jalote, (1991), "An integrated approach to software engineering,1991 Edition" : Narosa Publishing House, New Delhi.

2. Michael R Blaha and James R, (2004), “Object Oriented Modeling and Design with UML", $2^{\text {nd }}$ Edition. Prentice Hall.

3. Herbert Schildt, (2007), "The Complete Reference Java Seventh Edition", The McGraw-Hill Companies.

4. Ivan Bayross, "Web Development Commercial Application Development using HTML", $22^{\text {nd }}$ Revise Edition, BPB Publication.

5. John Horton, (2015), “Android Programming for Beginners", 2015 Packt Publishing

\section{WEBSITES}

https://www.tutorialspoint.com/mysql/ https://www.simplifiedcoding.net/android-login-andregistration-tutorial/

https://androidjson.com/recyclerview-json-listview-example/ https://www.tutorialspoint.com/google_maps/google_maps_ markers.htm

https://www.simplifiedcoding.net/android-form-validationtutorial/

https://www.w3schools.com/html/html_scripts.asp

https://www.color-hex.com/color-palettes/

https://www.sitepoint.com/html5-form-validation

\section{AUTHORS PROFILE}

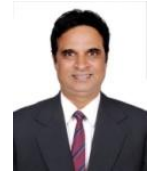

Mr. Sajfan, Department of MCA, Shree Devi Institute of Technology, Mangalore, Karnataka, India.

Dr. K. E. Prakash has over 30 years of experience in teaching, research and administration in Engineering education. He obtained his B.E. Degree from Mysore University, M.E. from Gulbarga University, MIT (Information Technology) from MAHE University, Manipal, MCA from Punjab Technical University and Ph.D. from Kuvempu University. At present he is working as Director of Shree Devi Institute of Techonology, Mangalore. He has served VTU in many other capacities. He has published 45 research papers at National and International Journals and Seminars. He is a Life Member of Indian Society for Technical Education (ISTE), Fellow of Institute of Engineers (I), Member of Association of consulting Civil Engineers and Member of Mangalore Management Association. He was a President of Rotary Club of Sullia.

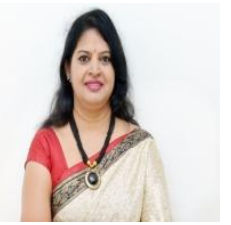

Dr. Nethravathi P.S has over 20 years of experience in teaching experience in teaching computer science of the graduates of various universities. She obtained Ph.D degree from Visvesvaraya Technological University, Belagavi, India. Presently she is working as a professor of Department of Master of Computer Applications at Shree Devi Institute of Technology, Mangalore. Her research area includes Data Mining, Business Intelligence and Natual Language Processing. She has published research papers in national and international journals. She is a Life Member of Indian Society for Technical Education (ISTE).

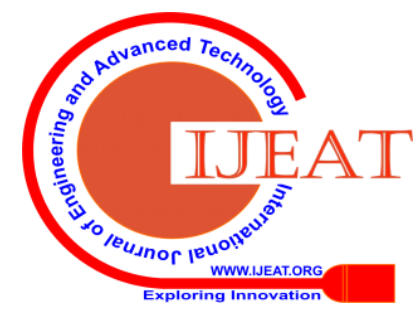

